\title{
Comparison of Metformin with Insulin in the Management of Gestational Diabetes
}

\author{
Syeda Masooma Bukhari ${ }^{1}$, Mishal Awan ${ }^{2}$, Iffat Ayoub ${ }^{3}$ \\ 1,2,3. House Officer, Nishtar Hospital, Multan. \\ Correspounding Author: masooma.bukh@gmail.com
}

\begin{abstract}
:
Objective: Purpose of this study is to determine the efficacy of metformin as opposed to insulin in management of gestational diabetes mellitus.

Methodology: The study took place in department of Gynecology and Obstetrics, Nishtar Hospital,Multan from May 2017 to March 2019. Study design is experimental prospective comparative study. Ethical approval was obtained from Hospital Ethics Committee. Sample was calculated using non probability consecutive sampling technique. Total 770 Patients were randomly divided into two equal groups, group M (metformin) and Group I (insulin). Glycemic control, mode of delivery and associated medical complication were recognized as possible maternal outcomes while congenital anomalies (if any), macrosomia, hypoglycemia, hyperbilirubinemia were the neonatal outcomes assessed by clinical and laboratory investigations. These outcomes were subjected to statistical analysis by using computer software SPSS version 23. Percentages were calculated for dichotomous variables and range, mean and standard deviation was calculated for continuous data. Chi square and t-test were applied to compare the two groups. P value less than 0.05 was considered as significant.
\end{abstract}

Results: Overall $100 \%(\mathrm{n}=770)$ female patients were included, in this study; divided into two equal groups $50 \%$ $(\mathrm{n}=385)$ in each i.e. metformin (Group M) and insulin (Group I). Significant difference was found between age $(p=0.000)$, gravidity $(p=0.012)$, gestational age $(p=0.000)$, BMI in early pregnancy $(p=0.000)$, FBS at entry $(p=0.000)$, FBS after treatment $(p=0.000)$, HBA1c at entry $(p=0.000)$, HBA1c after treatment $(p=0.000)$, in groups. Association was found between Preeclampsia $(\mathrm{p}=0.000)$, Pre-term birth $(\mathrm{p}=0.000)$, Neonatal birth weight $>4(\mathrm{p}=0.002)$, neonatal hypoglycemia $(\mathrm{p}=0.000)$, in groups.

Conclusion: This study concludes that metformin is as much effective as insulin in management of gestational diabetes mellitus. Metformin when used securely can prove effective as it does not cause any congenital anomalies or maternal or neonatal complications. But insulin still remains the gold standard for treatment of gestational diabetes mellitus.

Keywords: Diabetes Mellitus, Gestational Diabetes, Metformin, Insulin, Pregnancy

DOI: $10.7176 / \mathrm{JMPB} / 54-11$

Publication date: April $30^{\text {th }} 2019$

\section{Introduction:}

Glucose intolerance of any level with onset or first identified during the pregnancy can be called as gestational diabetes [1]. Overall morbidity of gestational diabetes is increasing with passing time. According to an estimate, 1 to $14 \%$ of all the pregnancies are complicated by gestational diabetes, which of course depends upon the size of the population under study, type of classification and diagnostic tests used [2]. Gestational diabetes is thought to have both short and long term outcomes which affect both mother and newly born child [3]. Out of the complications faced by the pregnant mother most common are preeclampsia, increased risk of developing diabetes mellitus type 2 after pregnancy and cesarean section. In case of neonatal morbidities, risk of neonatal loss becomes greater; there is also risk of still birth and congenital abnormalities, all because of excess glucose transfer from mother to fetus. Macrosomia is another major complication which can lead to shoulder dystocia during transvaginal birth, presenting a risk for instrumental deliveries, C-section and neonatal hypoglycemia later [4]. Intrauterine hyperglycemic environment may cause this condition to pass on to the children of the mother who is suffering from gestational diabetes [5]. That is why the aim of management of gestational diabetes is to control the glycemic levels and hence reduce the horrible post-pregnancy outcomes [6].

Possible treatments to reduce these complications can be enlisted as, exercise [7], diet modifications, insulin and oral hypoglycemic conditions. Up till now, insulin therapy has been considered as gold standard for treatment of 
gestational diabetes as diet modification with or without exercise is not enough to resolve this grave problem [8]. Although insulin is the treatment of choice but it does come with some side effects like weight gain, several injections per day and a risk of developing hypoglycemia [9]. So adjustments are made according to the BMI, lifestyle of the patient and blood glucose level. In other words, a detailed guidance is necessary regarding change in insulin dosages, so that self administration can be ensured to be safe. As expected, oral insulin therapy is much more satisfying and preferable in women with gestational diabetes, until its safe and effective.

Oral hypoglycemic drugs should also be considered especially in order to identify their effect on the final outcomes in both mothers and neonates. Metformin is first line of drug in the management of type 2 diabetes mellitus [10] and can be considered as another possible treatment option for gestational diabetes. But studies have shown a mother to fetus transfer of almost 10 to $16 \%$ in case of metformin [11] which poses a great risk to both mother and the fetus as chances of adverse effects in mothers and birth defects in newborn increases significantly. This is the reason metformin has not been used widely in gestational diabetes management.

Multiple studies have been performed in past in order to determine the efficacy and safety of metformin in management of gestational diabetes but most of these studies were cross-sectional and had smaller sample size which does not sufficiently describe the effect of metformin on maternal and neonatal outcomes. Thus, in this study our aim is to compare the efficacy of metformin with insulin therapy in gestational diabetes management, in terms of maternal and neonatal outcomes. Reference for this study was taken from a recent study performed by Hesham Borg et al [12].

\section{Materials and Methods:}

The study took place in department of Gynecology and Obstetrics, Nishtar Hospital,Multan from May 2017 to March 2019.. Study design is experimental prospective comparative study. Ethical approval was obtained from Hospital Ethics Committee. Sample was calculated using non probability consecutive sampling technique, using the reference study by Hesham Borg et al [12]. Confidence level was taken as $95 \%$ and power of study as $80 \%$ and mean and standard deviation of outcome variable postprandial blood sugar level was used to calculate the sample size. As a result 770 patients were taken as the required sample size for our study. Total no. of 770 patients was included in the study. Inclusion criteria described by Carpenter and Coustan was used to select the patients of gestational diabetes, according to which, blood glucose level must be, fasting $>95 \mathrm{mg} \backslash \mathrm{dl}$, at $1 \mathrm{hr}$ $>180 \mathrm{mg} \backslash \mathrm{dl}$, at $2 \mathrm{~h}>155 \mathrm{mg} \backslash \mathrm{dl}$ and at $3 \mathrm{~h}>146 \mathrm{mg} \backslash \mathrm{dl}$, along with Nishtar Hospital criteria to start insulin therapy. Those patients who were in labor, had contradiction against metformin or with fetal anomalies, preeclampsia, gestational hypertension, ruptured membranes or fetal growth restrictions were excluded from the study. Informed consent was taken from the patients before involving them into the study. Patients were randomly divided into two equal groups, group M (metformin) and Group I (insulin). Metformin was given to patients of group $\mathrm{M}$ as $500 \mathrm{mg}$ doselday orally in morning and increased by $500 \mathrm{mg}$ per week if required. Mixed human suspension of insulin was given as $0.7 \mathrm{U} \backslash \mathrm{kg}$ of body weight subcutaneously two times a day and was also increased as per requirement. Weekly examination of the patients was scheduled which involved, history taking, general physical examination and fasting blood sugar and postprandial blood sugar (glycemic profile). Weekly visit involved dose adjustments if required and provision of standard obstetric care. Basic facilities were provided at antenatal clinic level including ultrasound examination. Ultrasound examination was performed at first visit and then at 16 to 19 weeks ( $2^{\text {nd }}$ visit) and then monthly after 28 weeks of gestation. Glycemic control, mode of delivery and associated medical complication were recognized as possible maternal outcomes while congenital anomalies (if any), macrosomia, hypoglycemia, hyperbilirubinemia were the neonatal outcomes assessed by clinical and laboratory investigations. These outcomes were subjected to statistical analysis by using computer software SPSS version 23. Percentages were calculated for dichotomous variables and range, mean and standard deviation was calculated for continuous data. Chi square and t-test were applied to compare the two groups. $\mathrm{P}$ value less than 0.05 was considered as significant.

\section{Results:}

Overall 100\% ( $\mathrm{n}=770)$ female patients were included, in this study; divided into two equal groups $50 \%$ $(\mathrm{n}=385)$ in each i.e. metformin (Group M) and insulin (Group I). The mean age, gravidity, parity, gestational age, BMI in early pregnancy and BMI during treatment of the patients of group M was $24.92 \pm 2.57$ years, $2.57 \pm 1.17,1.48 \pm 0.66,27.94 \pm 2.57$ weeks, $22.08 \pm 2.98 \mathrm{~kg} / \mathrm{m}^{2}$ and $31.88 \pm 2.26 \mathrm{~kg} / \mathrm{m}^{2}$ respectively. While, the mean age, gravidity, parity, gestational age, BMI in early pregnancy and BMI during treatment of the patients of group I was $28.01 \pm 2.53$ years, $2.35 \pm 1.19,1.41 \pm 1.06,29.92 \pm 2.27$ weeks, $23.82 \pm 2.81 \mathrm{~kg} / \mathrm{m}^{2}$ and $32.05 \pm 1.89 \mathrm{~kg} / \mathrm{m}^{2}$ respectively. (Table1).

The Mean \pm S.D FBS at entry, FBS after treatment, 2hPPBS at entry, 2hPPBS after treatment, HBA1c at entry and HBA1c after treatment of the patients of group $M$ was $130.06 \pm 10.34 \mathrm{mg} / \mathrm{dl}, 82.28 \pm 5.51 \mathrm{mg} / \mathrm{dl}$, 
$175.18 \pm 7.89 \mathrm{mg} / \mathrm{dl}, 111.94 \pm 7.02 \mathrm{mg} / \mathrm{dl}, 5.73 \pm 0.54 \mathrm{mg} / \mathrm{dl}$ and $5.08 \pm 0.42 \mathrm{mg} / \mathrm{dl}$ respectively. While, the Mean \pm S.D FBS at entry, FBS after treatment, 2hPPBS at entry, 2hPPBS after treatment, HBA1c at entry and HBA1c after treatment of the patients of group I was $122.37 \pm 9.94 \mathrm{mg} / \mathrm{dl}, 76.88 \pm 7.75 \mathrm{mg} / \mathrm{dl}, 174.46 \pm 6.02 \mathrm{mg} / \mathrm{dl}$, $112.34 \pm 5.02 \mathrm{mg} / \mathrm{dl}, 6.15 \pm 0.59 \mathrm{mg} / \mathrm{dl}$ and $5.71 \pm 0.49 \mathrm{mg} / \mathrm{dl}$ respectively. Gestational HTN $7.3 \%(\mathrm{n}=28)$ and $8.1 \%$ $(n=31)$, preeclampsia $4.4 \%(n=17)$ and $15.6 \%(n=60)$, pre-term birth $2.6 \%(n=10)$ and $12.5 \%(n=48)$, mode of delivery CS 40.8\% $(\mathrm{n}=157)$, NVD 59.2\% $(\mathrm{n}=228)$ and CS 36.1\% $(\mathrm{n}=139)$, NVD $63.9 \%(\mathrm{n}=246)$, neonatal birth weight $>410.9 \%(n=42)$ and $18.7 \%(n=72)$, neonatal hypoglycemia $28.3 \%(n=109)$ and $52.5 \%(n=202)$, neonatal Jaundice $51.2 \%(\mathrm{n}=197)$ and $39.7 \%(\mathrm{n}=153)$, were noted for the group M and I respectively. (Table 2).

Significant difference was found between age $(p=0.000)$, gravidity $(p=0.012)$, gestational age $(p=0.000), B M I$ in early pregnancy $(p=0.000), F B S$ at entry $(p=0.000), F B S$ after treatment $(p=0.000)$, HBA1c at entry $(p=0.000)$, HBA1c after treatment $(p=0.000)$, in groups.

Association was found between Preeclampsia $(\mathrm{p}=0.000)$, Pre-term birth $(\mathrm{p}=0.000)$, Neonatal birth weight $>4$ $(\mathrm{p}=0.002)$, neonatal hypoglycemia $(\mathrm{p}=0.000)$, in groups. (Table12).

Table 1

\section{Demographic Variables}

\begin{tabular}{|l|l|l|l|}
\hline Variable & $\begin{array}{l}\text { Metformin } \\
\mathbf{n}=(\mathbf{3 8 5}) \\
\text { Group A }\end{array}$ & $\begin{array}{l}\text { Insulin } \\
\mathbf{n}=\mathbf{( 3 8 5 )} \\
\text { (Group B) }\end{array}$ & Test of Sig. \\
\hline Age & $24.92 \pm 2.57$ years & $28.01 \pm 2.53$ years & $\begin{array}{l}\mathbf{t}=\mathbf{- 1 6 . 8 0} \\
\mathbf{p}=\mathbf{0 . 0 0 0}\end{array}$ \\
\hline Gravidity & $2.57 \pm 1.17$ & $2.35 \pm 1.19$ & $\begin{array}{l}\mathbf{t}=\mathbf{2 . 5 3} \\
\mathbf{p}=\mathbf{0 . 0 1 2}\end{array}$ \\
\hline Parity & $1.48 \pm 0.66$ & $1.41 \pm 1.06$ & $\begin{array}{l}\mathbf{t}=\mathbf{1 . 0 5} \\
\mathbf{p}=\mathbf{0 . 2 9 3}\end{array}$ \\
\hline $\begin{array}{l}\text { Gestational Age } \\
\text { BMI in early } \\
\text { pregnancy during }\end{array}$ & $22.08 \pm 2.98 \mathrm{~kg} / \mathrm{m}^{2}$ & $23.82 \pm 2.81 \mathrm{~kg} / \mathrm{m}^{2}$ & $\begin{array}{l}\mathbf{t}=\mathbf{- 1 1 . 3 0} \\
\mathbf{p}=\mathbf{0 . 0 0 0}\end{array}$ \\
\hline $\begin{array}{l}\text { BMI }=\mathbf{- 8 . 3 2 3} \\
\mathbf{p}=\mathbf{0 . 0 0 0}\end{array}$ \\
treatment
\end{tabular}

\section{Discussion:}

Prevalence of gestational diabetes varies within different races and it depends upon diagnostic tests used for its diagnosis. Use of a specific diagnostic criterion and a certain ethnic background suggests that gestational diabetes incidence varies from 2 to $8 \%$ [13]. Gestational diabetes has been reported to associate with many maternal and perinatal complications including, preeclampsia, macrosomia, shoulder dystocia, hypoglycemia, cesarean section, birth injuries and respiratory distress syndrome [14, 15]. Multiple studies have shown that risk of these complication rises with the rise in blood glucose level and that these complications can be prevented by proper management of hyperglycemia which is the major finding of gestational diabetes [16, 17]. Recommendations regarding diagnosis and management of gestational diabetes are derived from American College of Obstetricians and Gynecologists and American Diabetes Association in attempt to avoid these unpleasant outcomes $[18,19]$.

Women suffering from gestational diabetes who were unable to be treated with diet modifications and exercise recommendations are traditionally treated by insulin therapy [20]. But insulin therapy carries risk of weight gain, difficulty for pregnant women as multiple injections are required daily and also there is risk of developing hypoglycemia. Therefore metformin is considered as a replacement therapy and it is also effective in gestational diabetes [21]. There are no risks of developing hypoglycemia and gaining of weight with use of metformin and metformin acts by preventing peripheral insulin resistance and diminishing gluconeogenesis in liver [22].

According to a meta-analysis, there was no risk of major congenital anomalies associated with metformin. Other studies also gave the conclusion that oral hypoglycemic agents when compared with insulin are not much different from insulin therapy in terms of maternal or neonatal outcomes, in women with gestational diabetes $[23,17]$. 
Table 2

Comparison between groups with respect to pattern of blood sugar level, maternal and neonatal complications and mode of delivery

\begin{tabular}{|c|c|c|c|}
\hline Variable & \begin{tabular}{|l|} 
Metformin \\
$\mathbf{n}=(\mathbf{3 8 5})$ \\
Group A \\
\end{tabular} & $\begin{array}{l}\begin{array}{l}\text { Insulin } \\
\mathbf{n}=(\mathbf{3 8 5}) \\
\text { (Group B) }\end{array} \\
\end{array}$ & Test of Sig. \\
\hline FBS at entry & $130.06 \pm 10.34 \mathrm{mg} / \mathrm{dl}$ & $122.37 \pm 9.94 \mathrm{mg} / \mathrm{dl}$ & $\begin{array}{l}t=10.53 \\
p=0.000\end{array}$ \\
\hline $\begin{array}{ll}\text { FBS } & \text { after } \\
\text { treatment } & \\
\end{array}$ & $82.28 \pm 5.51 \mathrm{mg} / \mathrm{dl}$ & $76.88 \pm 7.75 \mathrm{mg} / \mathrm{dl}$ & $\begin{array}{l}t=11.15 \\
p=0.000\end{array}$ \\
\hline 2hPPBS at entry & $175.18 \pm 7.89 \mathrm{mg} / \mathrm{dl}$ & $174.46 \pm 6.02 \mathrm{mg} / \mathrm{dl}$ & $\begin{array}{l}t=1.42 \\
p=0.157\end{array}$ \\
\hline $\begin{array}{ll}\text { 2hPPBS } & \text { after } \\
\text { treatment }\end{array}$ & $111.94 \pm 7.02 \mathrm{mg} / \mathrm{dl}$ & $112.34 \pm 5.02 \mathrm{mg} / \mathrm{dl}$ & $\begin{array}{l}t=-0.909 \\
p=0.364\end{array}$ \\
\hline HBA1c at entry & $5.73 \pm 0.54 \mathrm{mg} / \mathrm{dl}$ & $6.15 \pm 0.59 \mathrm{mg} / \mathrm{dl}$ & $\begin{array}{l}t=-10.04 \\
p=0.000\end{array}$ \\
\hline $\begin{array}{l}\text { HBA1c } \\
\text { treatment }\end{array}$ & $5.08 \pm 0.42 \mathrm{mg} / \mathrm{dl}$ & $5.71 \pm 0.49 \mathrm{mg} / \mathrm{dl}$ & $\begin{array}{l}t=-19.11 \\
p=0.000\end{array}$ \\
\hline Gestational HTN & $7.3 \%(n=28)$ & $8.1 \%(n=31)$ & $\begin{array}{l}\chi^{2}=0.165 \\
p=0.684\end{array}$ \\
\hline Pre-eclampsia & $4.4 \%(n=17)$ & $15.6 \%(n=60)$ & $\begin{array}{l}\chi^{2}=26.68 \\
P=0.000\end{array}$ \\
\hline Pre-term birth & $2.6 \%(\mathrm{n}=10)$ & $12.5 \%(\mathrm{n}=48)$ & $\begin{array}{l}\chi^{2}=26.93 \\
P=0.000\end{array}$ \\
\hline Mode of delivery & $\begin{array}{l}\text { CS } 40.8 \%(n=157), \\
\text { NVD } 59.2 \%(n=228)\end{array}$ & $\begin{array}{l}\text { CS 36.1\% }(n=139), \\
\text { NVD } 63.9 \%(n=246)\end{array}$ & $\begin{array}{l}\chi^{2}=1.778 \\
P=0.182\end{array}$ \\
\hline $\begin{array}{l}\text { Neonatal birth } \\
\text { weight }>4\end{array}$ & $10.9 \%(n=42)$ & $18.7 \%(\mathrm{n}=72)$ & $\begin{array}{l}\chi^{2}=9.27 \\
\mathbf{P}=0.002\end{array}$ \\
\hline $\begin{array}{l}\text { Neonatal } \\
\text { hypoglycemia }\end{array}$ & $28.3 \%(n=109)$ & $52.5 \%(n=202)$ & $\begin{array}{l}\chi^{2}=46.65 \\
P=0.000\end{array}$ \\
\hline Neonatal Jaundice & $51.2 \%(\mathrm{n}=197)$ & $39.7 \%(n=153)$ & $\begin{array}{l}\chi^{2}=10.14 \\
P=0.001\end{array}$ \\
\hline
\end{tabular}

A study by Rai et al. [24] demonstrated that although insulin showed slightly better results, even then the difference was not statistically significant ( $\mathrm{p}=0.08-069)$. In this study it was also found that adjusted glucose levels were significantly reduced in group of patients treated with metformin as compared to those treated with insulin ( $\mathrm{p}=<0.001-0.003)$ after treating for one week. In other words metformin was uniform in controlling glucose level in comparison to insulin. But drawback of this particular prospective study was that sample size was not large enough.

Ijas $\mathrm{H}$ et al. [25] demonstrated that among the patients treated with metformin $32 \%$ required additional insulin to reach the normal blood glucose level. The observations suggest that women who needed additional insulin were mostly more obese, required earlier medical treatment and had higher fasting blood sugar levels as compared to the women who only required metformin to reach normal glucose levels. These findings suggest that these women had higher insulin resistance. 


\section{Conclusion:}

This study concludes that metformin is as much effective as insulin in management of gestational diabetes mellitus. Metformin when used securely can prove effective as it does not cause any congenital anomalies or maternal or neonatal complications. But insulin still remains the gold standard for treatment of gestational diabetes mellitus.

\section{Conflict of Interest:}

Nil

\section{Funding Source:}

Nil

\section{References:}

1- American Diabetes Association. Diagnosis and classification of diabetes mellitus. Diabetes Care. 2014 Jan 1;37 Suppl 1:S81-90.

2- DeSisto CL, Kim SY, Sharma AJ. Prevalence Estimates of Gestational Diabetes Mellitus in the United States, Pregnancy Risk Assessment Monitoring System (PRAMS), 2007-2010. Prev Chronic Dis. 2014;11:E104.

3- Ovesen PG, Jensen DM, Damm P, Rasmussen S, Kesmodel US. Maternal and neonatal outcomes in pregnancies complicated by gestational diabetes. A nation-wide study. J Matern Fetal Neonatal Med. 2015 Sep 22;28(14):1720-4.

4- Mortier I, Blanc J, Tosello B, Gire C, Bretelle F, Carcopino X. Is gestational diabetes an independent risk factor of neonatal severe respiratory distress syndrome after 34 weeks of gestation? A prospective study. Arch Gynecol Obstet. 2017 Sep 25;1-7.

5- Tomar AS, Tallapragada DS, Nongmaithem SS, Shrestha S, Yajnik CS, Chandak GR. Intrauterine programming of diabetes and adiposity. Current obesity reports. 2015 Dec 1;4(4):418-28.

6- Poomalar GK. Changing trends in management of gestational diabetes mellitus. World J Diabetes. 2015 Mar 15;6(2):284-95.

7- Padayachee C, Coombes JS. Exercise guidelines for gestational diabetes mellitus. World J Diabetes. 2015 Jul 25;6(8):1033-44.

8- Magon N, Seshiah V. Gestational diabetes mellitus: insulinic management. J Obstet Gynecol India. 2014 Apr 1;64(2):82-90.

9- Camelo Castillo W, Boggess K, Stürmer T, Brookhart MA, Benjamin DK, Funk MJ. Association of adverse pregnancy outcomes with glyburide vs insulin in women with gestational diabetes. JAMA Pediatr. 2015 May 1;169(5):452-8.

10- Copeland KC, Silverstein J, Moore KR, Prazar GE, Raymer T, Shiffman RN, Springer SC, Thaker VV, Anderson M, Spann SJ, Flinn SK. Management of newly diagnosed type 2 diabetes mellitus (T2DM) in children and adolescents. Pediatrics. 2013 Feb 1;131(2):364-82.

11 - Ryu RJ, Hays KE, Hebert MF. Gestational diabetes mellitus management with oral hypoglycemic agents. InSeminars in perinatology 2014 Dec 31 (Vol. 38, No. 8, pp. 508-515). WB Saunders.

12- Borg H, Ezat S. Metformin Opposed to Insulin in the Management of Gestational Diabetes. Res Obstet Gynecol. 2016;4(2):17-26.

13- HAPO Study Cooperative Research Group ${ }^{1}$, Metzger BE, Lowe LP, Dyer AR, Trimble ER, Chaovarindr U, et al. Hyperglycemia and adverse pregnancy outcomes. N Engl J Med. 2008 May 8;358(19):1991-2002.

14- Contreras M, Sacks DA, Bowling FG, Cowley DM, Liley H, McIntyre HD, Tudehope DI, HAPO Study Cooperative Research Group. The hyperglycemia and adverse pregnancy outcome (HAPO) study. Int J Gynecol Obstet. 2002;78(1):69-77.

15- Homko CJ, Reece EA. Insulins and oral hypoglycemic agents in pregnancy. J Matern Fetal Neonatal Med. 2006 Jan 1;19(11):679-86. 
16- Rowan JA, Gao W, Hague WM, McIntyre HD. Glycemia and its relationship to outcomes in the metformin in gestational diabetes trial. Diabetes Care. 2010 Jan 1;33(1):9-16.

17- Nicholson W, Bolen S, Witkop CT, Neale D, Wilson L, Bass E. Benefits and risks of oral diabetes agents compared with insulin in women with gestational diabetes: a systematic review. Obstet Gynecol. 2009 Jan 1;113(1):193-205.

18- American College of Obstetricians and Gynecologists. Gestational diabetes. ACOG practice bulletin no. 30. Obstet Gynecol. 2001;98(3):525-38.

19- American Diabetes Association. The American Diabetes Association (ADA) has been actively involved in the development and dissemination of diabetes care standards, guidelines, and related documents for many years. Introduction. Diabetes care. 2009 Jan;32:S1.

20- Nicholson W, Baptiste-Roberts K. Oral hypoglycaemic agents during pregnancy: the evidence for effectiveness and safety. Best Pract Res Clin Obstet Gynaecol. 2011 Feb 28;25(1):51-63.

21- Glueck CJ, Goldenberg N, Wang P, Loftspring M, Sherman A. Metformin during pregnancy reduces insulin, insulin resistance, insulin secretion, weight, testosterone and development of gestational diabetes: prospective longitudinal assessment of women with polycystic ovary syndrome from preconception throughout pregnancy. Human Reproduction. 2004 Mar 1;19(3):510-21.

22- Wensel TM. Role of metformin in the treatment of gestational diabetes. Annals of Pharmacotherapy. 2009 May;43(5):939-43.

23- Gilbert C, Valois M, Koren G. Pregnancy outcome after first-trimester exposure to metformin: a metaanalysis. Fertility and sterility. 2006 Sep 30;86(3):658-63.

24- Rai L, Meenakshi D, Kamath A. Metformin-A convenient alternative to insulin for Indian women with diabetes in pregnancy. Indian J Med Sci. 2009;63(11):491-7.

25- Ijas H, Vääräsmäki M, Morin-Papunen L, Keravuo R, Ebeling T, Saarela T, et al. Metformin should be considered in the treatment of gestational diabetes: a prospective randomised study. BJOG. 2011 Jun 1;118(7):880-5. 